\title{
História como alegoria
}

\author{
PETER BURKE
}

$\mathrm{N}$ ESTE ARTIGO, trata-se de um fenômeno recorrente na história da escrita da História, que parece não ter recebido a atenção que certamente merece, e que é a percepção e representação de um evento ou de um indivíduo do passado em forma de outro evento ou outro indivíduo. O estudo focaliza as diferentes circunstâncias nas quais se tecem comentários a respeito de um evento (usualmente no passado) quando os comentadores estão, na realidade, ou mais intensamente, interessados em outro (usualmente no presente). O principal objetivo do estudo refere-se a obras de História, mas é fato ser impossível isolar tais produções de outras narrativas ou mesmo representações visuais do passado. $\mathrm{Na}$ verdade, o modo mais direto de penetrar no assunto é comentar algumas imagens.

O primeiro exemplo é bem conhecido. Vem da série de afrescos do Vaticano, pintados por Rafael e seus assistentes, representando os papas Leão III e Leão IV. Leão III está coroando Carlos Magno, enquanto Leão IV está agradecendo a Deus pela vitória sobre os sarracenos. A ambos os papas foram imprimidas as feições de Leão $\mathrm{X}$, que encomendou os afrescos. O nome Leão e o inconfundível rosto cheio e olhos saltados tornam os paralelos inusitadamente explícitos . Em certo sentido, portanto, Leão III e Leão IV devem representar Leão X. O observador certamente tem o direito de suspeitar que as histórias pictóricas de Carlos v e sarracenos são alegorias das relações de Leão X com o Imperador Carlos V e Império Otomano (Jones \& Penny, 1983:150).

O discípulo de Rafael, Perino del Vaga, deu prosseguimento à série, pintando afrescos semelhantes no Castelo de Sant'Angelo, representando o Papa Paulo III, anteriormente Alessandro Farnese, como São Paulo e como Alexandre, o Grande (Harprath, 1981). Certamente, há muitos outros exemplos do que os historiadores da arte chamam de retratos alegóricos ou retratos de identificação (Polleross, 1988).

O segundo exemplo é mais exótico, mas também pertence a uma bemconhecida classe de imagens. Trata-se de outro afresco, desta vez do fim do século XVI, num mosteiro da Moldávia (Sucevita, para ser exato), mostrando os israelitas atravessando o Mar Vermelho. As tropas do Faraó, em perseguição, estão usando uniformes poloneses. Isto poderia ser nada mais que um anacronismo tradicional de uma parte da Europa, onde a Renascença e o sentido renascentista do passado não haviam ainda penetrado muito profundamente (Burke, 1969). 
Contudo, é também possível (provável mesmo), que o artista estivesse fazendo uma afirmação política, salientando um tópico. A pintura data aproximadamente do tempo de Miguel, o Corajoso, príncipe de Moldávia e Wallachia, um líder cuja bravura foi exibida nas batalhas com os poloneses. A pintura nos sugere claramente que Miguel está do lado de Deus e pode mesmo sugerir que os moldavos são o povo por Ele escolhido. Poder-se-ia compará-la com um quadro holandês, o da travessia do Mar Vermelho, pintado durante a revolta dos Países Baixos, época em que alguns cidadãos da nova república a entenderam e representaram como uma segunda Israel (e o seu inimigo, Felipe da Espanha, como um novo Faraó) (Schama, 1987:111).

A iconografia em si é uma espécie de Mar Vermelho, e um amador como eu não tem o direito de esperar que as águas se partam a fim de que possa atingir sua meta com segurança. Voltemo-nos, pois, para os textos literários, nos quais o uso da história como alegoria é um pouco mais explícito, pelo menos ocasionalmente.

Quase na mesma época em que o artista anônimo moldavo pintava o seu afresco, muitos ingleses se preocupavam com o problema do sucessor de sua rainha. Quando havia dúvidas sobre a sucessão, como se sabe, o resultado eram freqüentes guerras civis. Neste ponto, tanto poetas quanto historiadores - Samuel Daniel, Michael Drayton, sir John Hayward e William Shakespeare - ocupavam-se com as guerras civis inglesas do fim da Idade Média - A Guerra dos Barões, do século XIII, a Guerra das Rosas, e a deposição de Ricardo II por Henrique de Lancaster.

Seja qual tenha sido a intenção de Shakespeare ao escrever Ricardo II, sabemos que os seguidores do conde de Essex, que se rebelaram ao final do reinado de Elisabeth, viram a peça como um comentário sobre o presente, uma vez que haviam solicitado uma encenação especial (Albright, 1927). Tal como os rebeldes, a rainha não tinha dúvidas de que a figura de Ricardo II era alegórica. Quando fez a observação a William Lombard "Eu sou Ricardo II, não o sabeis?" (Neale, 1934:387), ela também perguntou a Francis Bacon "se não haveria traição contida" no livro de Hayward. Apesar da negativa de Bacon, Hayward foi para a prisão na Torre de Londres (Womersley, 1992:46-59).

Alguns anos depois, o próprio Bacon seguiria o exemplo de Hayward com mais sucesso, pois sua biografia de Henrique VII foi interpretada como uma alegoria de Jaime I (Bergeron, 1992:17-26). A história do mundo de sir Walter Raleigh, que tratava apenas da antigüidade, também tem sido interpretada como uma alegoria dos tempos modernos, numa interpretação apoiada pela famosa observação do autor segundo a qual é melhor não "seguir a verdade muito de perto", ou seja, é melhor não comentar sobre acontecimentos recentes por escrito.

Seria fácil multiplicar os exemplos, desde os primórdios da Europa moderna, de representações históricas que escondem ou implicam comentários sobre o 
presente, seja para lisonjear, justificar, advertir, seja para criticar um indivíduo ou um grupo. Os problemas começam quando tentamos explicar o que estava implícito, centenas de anos mais tarde. Por este motivo, o historiador volta-se com alívio para determinados exemplos cuja alegoria já tenha sido comentada pelos próprios contemporâneos.

Certo dia em 1625, por exemplo, o poeta Vondel estava conversando com um patrício de Amsterdam, Albert Burgh, sobre a execução - para não dizer assassinato jurídico - de uma figura proeminente na política holandesa, Johan van Oldenbarneveld, seis anos antes. "Escreva uma tragédia sobre o assunto", disse Burgh. "Ainda não chegou a hora", respondeu Vondel, que estava provavelmente receoso das possíveis conseqüências de tal ato. "É só mudar os nomes", foi a resposta de Burgh (Brandt, 1932:14). O resultado foi uma peça ambientada na Grécia antiga, a Palamedes, de Vondel. O inocente Palamedes, injuriado, representava claramente Oldenbarnevelt, enquanto Agamenon, também muito obviamente, retratava o príncipe de Orange.

Na França de Luís XIII e Luís XIV, era o governo e não a oposição que produzia as mais conhecidas alegorias da época. Dentre as obras que emanaram do círculo do cardeal de Richelieu, por exemplo, estavam duas biografias de cardeais-estadistas. Uma de Francisco Jiménez de Cisneros, e outra de Georges d'Amboise. Nos dois casos, a intenção alegórica é bastante transparente (Church, 1972).

Novamente, quando Luís XIV iniciou seu período de reinado pessoal, na década de 1660, o pintor da corte, Charles Lebrun, produziu cinco cenas tiradas da vida de Alexandre, o Grande, ao passo que Racine escrevia uma peça sobre o mesmo assunto. Neste caso, o objetivo do paralelo foi simplesmente o de glorificar o jovem rei, que teve prazer especial em se identificar com Alexandre (Grell \& Michel, 1988).

Em outros exemplos do tempo de Luís XIV, o motivo do empreendimento parece ter sido mais de advertência do que de glorificação. Britanicus, de Racine, implicava um paralelo entre Nero, aquele monstre naissant, e Luís, de tal modo chocante que ninguém, a não ser o rei, podia permitir-se perceber. Para ser exato, quase ninguém. Um contemporâneo registrou a observação de que após essa peça, que se refere ao desempenho de Nero no palco, Luís nunca mais dançou em público.

Seria tão fácil quanto tedioso multiplicar os exemplos desse tipo de alegoria histórica. A questão que mais preocupa um historiador cultural é se esse modo literário tem uma história, e se ela muda com o correr do tempo. O crítico norteamericano Angus Fletcher afirma que a "alegorização é um constante ... processo de representação" (Argan, 1980:18). Um de meus objetivos neste artigo é mostrar que esse ponto de vista requer qualificação. Meu argumento é que a alegoria 
difere não só em importância, mas também em significado de um período para outro, graças às mudanças de visão da relação entre os eventos representados, explícita ou implicitamente.

Poderá ser de valia começar por distinguir dois tipos ou dois usos de alegoria. O primeiro poderia ser chamado pragmático. Nestes casos, a alegoria é um meio para um fim, e não um fim em si. Quando meios diretos de comentário político são suprimidos, é hora de usar o método de Esopo, como costumavam dizer os poloneses no tempo de seu regime comunista.

No século XIX, apesar do domínio da doutrina da singularidade dos eventos históricos, a Cambridge Union, por exemplo, um clube de estudantes no qual não era permitido o debate de problemas políticos contemporâneos, discutia então os do século XVII. Novamente, foi observado que o quadro de Delaroche, Cromwell e Carlos I, exibido em Paris em 1831, refere-se à revolução de 1830, quando Luís Felipe sucedeu a Carlos X (Haskell, 1971:109-120).

Exemplo famoso do método de Esopo no século Xx é o filme de Eisenstein Ivan, o terrivel, cuja segunda parte (feita em 1946, e tratando da crescente paranóia do governante autoritário), não pode ser exibido em público até a morte de Stalin, tão óbvio era o paralelo entre passado e presente. Exemplo igualmente famoso da cultura de outro superpoder da época é a peça de Arthur Miller The crucible, sobre a caça às bruxas no estado de Massachusetts do século XVII, encenada pela primeira vez em 1953, durante a caça às bruxas da era do macartismo. Curiosamente, críticos contemporâneos não faziam referência aberta à política de seu próprio tempo. Não que fossem obtusos; nesse caso, suas escritas também têm de ser lidas alegoricamente.

Assim como ocorria nos séculos XVI e XVII, algumas obras eruditas modernas requerem também uma leitura alegórica além de uma literal. $\mathrm{O}$ falecido Arnaldo Momigliano, um dos grandes estudiosos clássicos de nosso século, confessou certa vez que sua preocupação com a liberdade grega, à época em que estava morando na Itália de Mussolini, era um gesto político. Ao mesmo tempo, outro historiador italiano, Francesco Ercole, estava escrevendo a respeito da crise de liberdade italiana, c.1500, a ditadura de Savonarola e seu uso político do movimento da juventude. Novamente, em 1965, um intelectual polonês, Leszek Kolakowski, publicou Cristãos sem igreja, um estudo de intelectuais dissidentes da Reforma que ansiavam pelo que poderíamos chamar de definhamento da Igreja. Sua relevância para os debates políticos na Polônia era bastante óbvia, e de qualquer forma o autor tornou suas opiniões explícitas um ano mais tarde, no décimo aniversário do regime Gomulka, antes de partir para o exílio (Kolakowski, 1969).

Parece que a alegoria pragmática é, se não uma presença constante, pelo menos um fenômeno recorrente na história cultural, emergindo sempre que necessário. Nesse sentido, a afirmativa de Fletcher é bastante válida. 
Contudo, alegorias históricas não podem ser reduzidas a tentativas de evitar censura. Um segundo tipo de alegoria poderia ser descrito como metafísico ou mistico, pois assume alguma espécie de conexão oculta ou invisível entre dois indivíduos ou eventos discutidos, por mais separados que estejam no espaço ou no tempo. Há uma óbvia analogia com a visão antiga, medieval e renascentista de correspondência entre o cosmos, o microcosmos e o corpo político. A idéia de que o rei é o sol, por exemplo, ou de que ele é a cabeça e o povo o corpo (ou os pés, como afirmou uma vez a rainha Elisabeth, num momento de exasperação com o parlamento).

O que se deve enfatizar é que, de acordo com essa visão, o presente é tido como uma espécie de replay ou reconstituição de acontecimentos passados. É como se, talvez Deus, estivesse escrevendo o nosso script. Esta é uma pressuposição subjacente no segundo tipo de alegoria. Como diz o antropólogo norte-americano Sahlins (1981:9), discutindo a percepção de capitão Cook pelos havaianos como uma reencarnação do seu deus Lono, "a história havaiana freqüentemente se repete, uma vez que só na segunda vez ela é um acontecimento. A primeira vez é um mito". Sua observação parece ser também aplicável à cultura ocidental. A questão que precisa ser discutida é se essa idéia em si tem uma história.

Comecemos com a Bíblia, na qual a interpretação linear dominante da história coexiste com a admissão da reencenação. No Velho Testamento, Josué, por exemplo, é apresentado como um novo Moisés, e assim também o é Elias. No Novo Testamento, a idéia de replay informa os Atos dos Apóstolos, os quais são regularmente descritos como revivendo a vida, a morte e a ressurreição de Cristo (Trompf, 1979).

Apesar do interesse em paralelos históricos, escritores gregos clássicos como Tucídides, Políbio, Plutarco, não parecem ter encarado a história em termos alegóricos. Em Vidas paralelas, de Plutarco, percebe-se, um exemplo não representa outro. Os romanos, em contrapartida, nesse caso, estavam mais próximos dos judeus. Virgílio escreveu de uma segunda Argo, e de Roma como uma nova Tróia. Em um nível implícito, a Eneida apresenta Augusto como um segundo Enéias. Virgílio parece estar fazendo muito mais do que chamar a atenção para certos paralelos entre os dois líderes. Ele parece estar sugerindo que é o destino de Augusto reviver a carreira de Enéias e re-fundar Roma.

A relação entre pares de eventos foi discutida em nível geral por rabinos e pelos pais da Igreja. Contudo, eles tinham mais a dizer sobre o inverso do que sobre a re-presentação. Uma forma de inversão é a idéia de cumprimento de uma profecia, quando o script, a história escrita, precede os acontecimentos em vez de segui-los. Numa segunda forma de inversão, um evento prefigura, anuncia, ou prenuncia um outro. Assim, os rabinos conceberam a redenção de Israel na era futura do Messias como prenunciada em cada detalhe na redenção do Egito (Hanson, 1959; Charity, 1966; Danielou, 1950; Pepin, 1958). 
De novo, Tertuliano e Agostinho estavam especialmente interessados em Typus, Allegoria, Figura, ou na famosa definição de Auerbach (1959), "algo real e histórico que anuncia alguma outra coisa que é também real e histórica”. Este vocabulário ainda estava em uso no começo do período moderno. A re-apresentação, por outro lado, carecia de uma descrição técnica do século XVII, quando o poeta alemão Andreas Gryphius apresentou o martírio do rei Carlos I como uma pós-figuração de Cristo (Gilbert, 1950; Powell, 1952). O termo pós-figuração não pegou. Na verdade, muito mais tarde, em 1968, um estudioso reivindicou para si a cunhagem do termo (Roston, 1968:69).

Mesmo assim, a idéia da re-apresentação era tão importante quanto seu oposto complementar, a pre-figuração, a partir da Idade Média, quer fossem os paradigmas aplicados a indivíduos, quer a lugares, quer a eventos. A maioria dos paradigmas era religiosa, mas exemplos seculares tornavam-se cada vez mais importantes, como as páginas seguintes tentarão mostrar.

Como nos Atos dos Apóstolos, Cristo permaneceu um modelo principal. Na crônica do século XI, de Rodolphus Glaber, o rei Roberto era descrito como imitador de Cristo (Nichols, 1983). Um dos cronistas da morte do arcebispo inglês Thomas Beckect, assassinado em sua catedral, descreve a paixão de seu herói (Knowles, 1949). Bartolomeu de Pisa escreveu um tratado da Conformidade da vida do abençoado Francis com a vida do Senhor Jesus.

Certos governantes também alcançaram statusparadigmático. Em Bizâncio, por exemplo, os últimos imperadores eram descritos como novos Constantinos (Treitinger, 1956:30). No Ocidente, Gregório de Tours também aplicou a descrição Novo Constantino a Clovis (Tanner, 1993:37). Carlos Magno também foi um Novo Constantino, mas, por sua vez, tornou-se um paradigma para descrições dos governantes que o seguiram. Por volta do ano 1000, por exemplo, o imperador Otto III foi descrito como um segundo Carlos Magno.

Em alguns desses casos, a descrição novo pode ter sido nada mais que uma comparação lisonjeira, mas sérias reivindicações de re-apresentação foram feitas. Profecias de um futuro, segundo Carlos Magno, eram correntes a partir do século XIV, nos escritos de Telesphorus de Cosenza, entre outros, e essas profecias se aplicaram sucessivamente a Carlos vi e Carlos VII da França, ao imperador Carlos v, e assim por diante (Reeves, 1969).

A série de paradigmas em uso no começo dos tempos modernos era muito rica. Carlos viII, da França, era representado como um novo Anibal, depois que atravessou os Alpes em 1494 (Chastel, 1981:77-102). Para Savonarola, ele era o novo Ciro. Não raro, um governante era descrito como um novo Josias (no caso de Eduardo vi da Inglaterra), um novo Salomão (no caso de Felipe II, da Espanha e de Jaime I, da Grã Bretanha ) ou um novo Davi, como no caso de Henrique VII, da Inglaterra, do imperador Maximiliano I, de Felipe II, de Guilherme de Orange. 
Esses paralelos não eram restritos a governantes. Hernán Cortez foi proclamado novo Cesar, um novo Josué, e um novo Moisés (Branding, 1991:116, 122 e 297). Peter Heylin apresentou William Laud (arcebispo da Cantuária) como o Cipriano inglês.

Os exemplos até agora têm sido todos masculinos, os femininos são relativamente raros. A raridade foi autoperpetuante, no sentido em que a predominância dos paradigmas masculinos deu a poucas mulheres, mesmo a rainhas, a oportunidade de serem descritas como uma outra personagem. Houve, contudo, significativas exceções a essa regra. Catarina de Médici, da França, foi retratada e descrita como a deusa Juno. A rainha Elisabeth I foi freqüentemente descrita como Astrea, a virgem associada à justiça e à Idade do Ouro (Yates, 1975:2997). Joana d'Arc, La Pucelle, foi vista como uma segunda Virgem Maria. Uma visionária do século XVI, Mère Jehanne, foi descrita pelo estudioso francês Guillaume Postel como uma nova Eva (Warer, 1981; Bouwsma, 1957). No início do período moderno é difícil saber quando levar a sério essas descrições, se tomálas como elogios elegantemente alusivos ou como expressões de esperanças e expectativas precisas. O problema para os intérpretes modernos é que o mesmo vocabulário foi usado por pessoas diferentes para expressar pontos de vista diferentes da relação entre velho e novo, da simples analogia à conexão mística.

É provável, contudo, que quando Carlos vII, da França, ou o imperador Carlos v, digamos, foi descrito como um segundo Carlos Magno, algo mais que uma simples comparação tenha sido a intenção, ainda que ocasional (Reeves, 1969:355; Weinstein, 1970). A semelhança dos nomes (como no caso dos papas chamados Leão) era por vezes interpretada como uma semelhança dos destinos. Por vezes, a relação entre dois governantes pode ter sido vista mais como uma pre-figuração do que uma re-apresentação, uma vez que, supostamente, Carlos Magno uniu o mundo num rebanho, coisa que o primeiro não tinha conseguido.

O problema da ambigüidade ocorre também no caso de cidades, tão freqüentemente descritas como novas Jerusalém, segundas Roma, e assim por diante. Para Eusébio de Cesarea, Constantinopla era uma nova Jerusalém. Para o cronista monástico francês Rodolphus Glaber, a nova Jerusalém era Orléans (Nichols, 1983). Para alguns florentinos do século XV, a sua própria cidade era a nova Jerusalém (Weinstein, 1970). A Londres medieval, como a Roma do tempo de Virgílio, era apresentada como a Nova Tróia pelo cronista Geoffrey of Monmouth, por exemplo. Carlos Magno foi descrito como fazendo sua cidade capital Aachen uma nova Atenas (de acordo com seu professor Alcuin), ou uma nova Roma (de acordo com seu biógrafo Einhard).

Muitas novas Romas se seguiram, incluindo Treves e Constantinopla (Hammer, 1994:50-62). Pádua foi descrita, no século XIII, como virtualmente uma segunda Roma (quasi secunda Roma) (Rolandino, apud Hyde, 1966:298). 
Reivindicação similar poderia ser feita para Praga no tempo de Carlos IV e para Florença no começo do século Xv, bem como para Milão e Veneza (Chambers, 1971; Marx, 1978). No século XVI, Sevilha também pretendeu ser uma nova Roma (Lleo Cañal, 1979). Da mesma forma o fizeram pequenas cidades como Enkhuizen, nos Países Baixos, onde na prefeitura ainda se pode ver, inscritas em ouro, as letras SPQE (seguindo o modelo de Senatus Populusque Romanus).

Que, em alguns casos pelo menos, a descrição não era uma simples comparação, pode-se ver no caso da reivindicação de Moscou como terceira Roma, formulada na famosa carta do abade Filofei de Pskov ao Tsar Basílio III (escrita em 1510) (Schaeder, 1929). Neste caso, havia séria reivindicação à herança de Roma e Constantinopla e afirmação de destino histórico.

A série de exemplos não deveria ser restrita à Europa. No fim do século XVI, Garcilaso de la Vega, o Inca, apresentou Cuzco como Nova Roma, um antigo exemplo do tipo de identificação que se tornaria característico das Américas (Nova Amsterdam, Nova Iorque, Nova Órleans, Atenas na Geórgia, Paris no Texas, Nova Friburgo, Nova Odessa, e assim por diante), nomes esses que devem ser interpretados seja como expressões de esperança, seja de nostalgia do velho mundo (Wachteel, 1977:44). Novamente, o problema é decidir até que ponto levá-los a sério, ou, mais exatamente, descobrir com que seriedade foram tomados nos diferentes séculos.

Não apenas cidades, mas nações inteiras foram identificadas com predecessores, especialmente os judeus. Em crônicas do fim da Idade Média, a França era apresentada como a Terra Santa, e os franceses como o povo escolhido (Strayer, 1969:3-16). Da mesma forma, no início dos tempos modernos, a Inglaterra era conhecida como a Nação Eleita, enquanto a República Holandesa era algumas vezes descrita como uma Nova Israel e a América apresentada como uma Nova Canã̃ (Haller, 1963; Groenhuis, 1981:118-133; Schama, 1987; Tuvenson, 1968). Nestes casos, como no de Moscou, as descrições eram afirmações de um papel histórico, um destino futuro.

O que se inferia dessas afirmações pode se tornar um pouco mais evidente se examinarmos com mais detalhes a idéia de re-encenação como um evento ou uma seqüência de eventos. Em nível de ritual, isto é lugar comum: a missa como representação da Paixão de Cristo, por exemplo. Contudo, a idéia de re-apresentação também afetou a percepção de eventos históricos. No século XII, por exemplo, o monge francês Guibert de Nogent descreveu as Cruzadas como um Novo Exxodo.

Novamente, o próprio conceito de uma Renascença da antigüidade clássica, a Renovatio, dependia da pressuposição da re-apresentação (Burdach, 1918; Borimski, 1919). O movimento que chamamos de renascimento foi na verdade uma enorme tentativa ou série de tentativas de re-apresentar as realizações da antigüidade clássica, enquanto a reforma foi uma tentativa coletiva 
de re-apresentar a história dos começos da Igreja. Que a idéia da Reforma (re-forma) foi mais do que uma metáfora é sugerida pelas obras de estudiosos como John Foxe e John Knox, que encaravam os eventos de seu tempo como o cumprimento de profecias bíblicas (Firth, 1979). De modo semelhante, as celebrações do centenário da Reforma, na Alemanha em 1617, representaram o evento como cumprimento do que haviam predito as Escrituras (Jürgen, 1978:89, 200, 254).

Paralelos implícitos entre acontecimentos distantes no passado também subjazem a um número de estudos históricos publicados na Europa, no século XVII, cujas alegorias sejam pragmáticas ou sejam metafísicas. Na República Holandesa, por exemplo, Gerard Vossius publicou a história da controvérsia entre Agostinho e os Pelágios no tempo do Sínodo de Dort em 1618. Em 1682, o teólogo Samuel Johnson publicou um estudo sobre Juliano, o apóstota, que discutia o problema da obediência passiva na igreja primitiva e obviamente se referia à Crise Britânica de Exclusão (muito obviamente, de vez que o autor foi preso e açoitado). Na França, em 1709, durante a Guerra da Sucessão Espanhola, o propagandista e crítico de arte Jean-Baptiste Du Bos escreveu uma história da Liga de Cambrai contra Veneza 200 anos antes.

O ponto a enfatizar é que pelo menos algumas pessoas esperavam a representação de dramáticos episódios históricos cena por cena. Na França, por exemplo, as guerras religiosas eram tidas pelos protestantes como uma re-apresentação das perseguições sofridas pelo povo de Deus, tal como descritas na Bíblia. Em gerações posteriores, lembravam-se do Massacre de São Bartolomeu, no qual foram mortos muitos protestantes, como um Segundo Massacre dos Inocentes (Joutard, 1976). As guerras também eram vistas como re-apresentações das guerras civis da Roma antiga, com um novo Triunvirato no lugar do antigo. Por exemplo, um quadro no Louvre, pintado por Antoine Caron (circa 1562), representa um incidente da história romana, o massacre dos triúnviros (isto é, ordenada pelos triúnviros). Essa alusão aos feitos do assim chamado triumvirato, nos primórdios das guerras religiosas francesas torna-se mais transparente pela inclusão anacronística na Roma antiga de uma fortaleza papal, o Castelo de Sant'Angelo.

Novamente, na década de 1640, a guerra civil inglesa foi sentida como um replay das guerras religiosas francesas. Um cavalheiro inglês fez a observação de que havia sido emprestada a história daquelas guerras, de Enrico Davila, com “o título de O Vade Mecum do sr. Hampden; e eu creio que nenhuma cópia foi (mais) fiel ao original do que aquela rebelião foi à nossa" (Salmon, 1959:100).

Um pensamento semelhante ocorreu a muitos ingleses à época da assim chamada Crise de Exclusão, quando foi feita uma tentativa para excluir da sucessão ao trono o católico Jaime, duque de York, irmão mais moço de Carlos II. Nessa ocasião, John Dryden (mais conhecido hoje por sua alegoria bíblica Absalom and Achitofel) escreveu - ou pelo menos colaborou com - a peça $O$ duque de 
Guise para mostrar o paralelo entre a França em 1583 e a Inglaterra em 1683, com o conde de Shaftesbury no lugar do duque e os dissidentes no lugar da Liga Católica. Foi, naturalmente, uma cópia ao inverso, com protestantes extremados no lugar de católicos ferrenhos, mas a ameaça à autoridade de Carlos II e à de Henrique III foi a mesma.

Carlos II gostou da peça e pediu a Dryden que traduzisse uma história recente da Liga Católica. Dedicando sua tradução ao rei, Dryden sugeriu que "as características são as mesmas em tudo", no caso dos eventos de 1584 e 1684. Mesmo assim, não fica muito claro que paralelo Dryden está estabelecendo, se ele está pensando em semelhanças (que realmente são marcantes) ou em correspondências ocultas, ou conexões (como sugerem as referências às datas de 1584 e 1684) (Zwicker, 1984). Fica menos evidente ainda se ele esperava que o curso da história inglesa seguisse o modelo francês (o assassinato do duque de Guise, o assassinato de Henrique III, e assim por diante).

Um motivo para a dificuldade de interpretar as intenções de Dryden é o final do século XVII ser um período em que a tradicional teoria das correspondências entre microcosmos, macrocosmos e assim por diante é tida, por estudiosos modernos, como decadente e substituída por uma nova maneira de pensar representada por Galileu, Descartes, Bayle, entre muitos outros (Hazard, 1947; Willey, 1934). Como disse Marjorie Nicolson, uma norte-americana historiadora da ciência, "nossos ancestrais acreditavam que o que chamamos analogia (grifos do autor) era verdade, inscrita por Deus na natureza das coisas". Essa crença é hoje questionada (Nicolson, 1950:108; Foucault, 1970; Harris, 1966).

Intelectuais, como Pierre Bayle, que duvidavam que cometas fossem realmente sinais e eram céticos sobre as correspondências entre microcosmos e macrocosmos, provavelmente também duvidassem de correspondências históricas. O livro da história, bem como o da natureza, estavam para ser interpretados literalmente ao invés de alegoricamente, como parte de um "surgir de uma inclinação à literalidade" (Burke, 1993:108-121). Analogias eram ainda estabelecidas, mas seu status lógico mudou. Cada vez mais se acreditava que eram mais subjetivas que objetivas.

É difícil calcular a rapidez dessa mudança de atitude ou mentalidade. É provável que católicos, como Carlos II que havia sido apresentado como um novo Davi na sua coroação, ou Dryden (a despeito de seu conhecimento das obras dos céticos), continuaram a pensar da velha maneira (Reedy, 1972; Bredvold, 1934). Assim o fizeram os calvinistas, entre os quais o pastor Pierre Jurieu, que se referia ao holandês, rei da Inglaterra, Guilherme III, como a um segundo Moisés, ou a um segundo Davi (Gibbs, 1975). 
Pelo menos a mudança de direção está clara. Até o século XVIII é difícil encontrar rejeição de alegoria, ou reivindicações tradicionais de alegoria, desde as discussões de Shaftesbury sobre o tópico no começo desse século, até a rejeição de Joseph Spencer das alegorias de Cesare Ripa e Edmund Spenser em 1747 (Schöne, 1964; Gordon, 1975:51-74; Paulson, 1975). A crescente importância, no século XIX, da doutrina da singularidade dos eventos, que Meinecke (1972) chamou de historismo (Historismus) debilitou ainda mais a alegoria metafísica. Não foram somente historiadores que professaram essa doutrina; a idéia moderna de revolução, que data de aproximadamente 1789, é a de mudança irreversível, de uma ruptura com o passado bem simbolizada pela decisão dos revolucionários franceses de mudar o calendário e começar com o Ano 1.

Contudo... esta história é simples demais. As alegorias históricas dos últimos três séculos não são todas reduzíveis ao pragmatismo. É difícil, se não impossível, perceber ou lembrar de algo sem o uso de algum tipo de esquema mental, incluindo o que poderíamos chamar de esquema mestre, ou a organização de mitos de determinada cultura.

A Revolução Francesa, por exemplo, foi sentida por alguns contemporâneos como uma repetição da história romana antiga, como uma expulsão de um novo Tarquino. As revoluções francesas de 1830, 1848 e de 1871, por sua vez, foram vistas como re-apresentações de 1798. De maneira semelhante, a Revolução Russa foi sentida (por Trotsky, entre outros) como um replay da Revolução Francesa. Também a Guerra Civil Espanhola foi vista por alguns participantes como re-encenação da Revolução Russa.

Os historiadores também acham difícil evitar paralelos dessa natureza, mesmo quando afirmam acreditar na singularidade dos eventos. Como já provou White (1973), eles colocam a história em enredos, pelo menos ocasionalmente, de acordo com os modelos da épica, do romance, da comédia e da tragédia, modelos que implicam re-apresentação, mesmo que não estejam sempre conscientes de que o estejam fazendo.

O que é ao mesmo tempo fascinante e espicaçante sobre os exemplos mais recentes é a dificuldade de decidir como interpretar alegorias. Eu ousaria dizer que há uma pós-figuração em torno delas, um sentido de re-apresentação de um evento exemplar, mesmo que não possa ser admitido em nossa era, mais inclinada à literalidade. Esta preocupação com a re-apresentação está particularmente clara no historiador vitoriano E. A. Freeman, para quem a história inglesa era "um drama de renascimento e ressurreições", com Simon of Montfort, por exemplo, que liderou os barões em revolta contra o rei Henrique III, como uma nova versão do líder anglo-saxão Conde Godwin, que liderou a oposição ao rei Eduardo, o Confessor (Burrow, 1981:221). 
Um grupo final de exemplos pode reforçar essa idéia. Alexandre Nevsky (1938) de Eisenstein, ao contrário de seu Ivan, o terrivel, não precisa enganar o censor. Contudo, sua celebração da capacidade da nação de derrotar seus invasores ganha no que chamamos de ressonância ao evocar o passado russo distante. $\mathrm{E}$, outra vez, o filme de Lawrence Olivier, baseado na peça Henrique $V$, de Shakespeare, não foi uma alegoria pragmática. Ainda assim, foi interpretada na época, final da Segunda Guerra Mundial, como uma afirmativa sobre o presente. Crianças, eu inclusive, eram levadas pelas escolas para ver o filme. Éramos encorajados a ver os desembarques do Dia D como uma repetição da batalha de Agincourt, quando Deus estava do lado dos ingleses.

De maneira semelhante, por outro lado, o filme de Mizoguchi The forty seven ronin (1941), que narra o suicídio de um grupo de samurais leais, no começo do século XVIII, teve igual relevância contemporânea. O filme foi feito muito cedo para ser interpretado como apoio da entrada do Japão na Segunda Guerra Mundial, ou mesmo para encorajar os pilotos kamikazen em suas missões suicidas; serviu pelo menos para lembrar ao povo japonês as suas tradições de sacrifício.

Não há necessidade de terminar com a Segunda Guerra Mundial. Até hoje, a cada mês de dezembro, os protestantes moradores de Derry - que eles chamam de Londonderry - realizam seu ritual tradicional para comemorar o cerco de 1688-89. O ritual tem seu efeito na vida diária. Alguns protestantes irlandeses se referem ao período corrente, de dificuldades, longo como se fosse o cerco. Eles usam a frase sem rendição para se referirem não à cidadela, mas à sua recusa em aceitar a solução para o problema da Irlanda do Norte em termos de compromisso. Escrevem nas paredes da casa: Lembre-se de 1690, referindo-se à vitória de Guilherme III e dos protestantes na batalha de Boyne. Em outras palavras, eles vêem o presente como uma repetição do passado (Buckely, 1989:183-197). Como suas atitudes diferem das de Dryden, ou mesmo das dos havaianos que, se supõe, viram a chegada do capitão Cook como a epifania de um deus? (Sahlins, 1985: Obeyesekere, 1992).

Referências bibliográficas

ALBRIGHT, L.M. Shakespeare's Richard II and the Essex conspiracy. Publicação da Associação de Linguagem Moderna, 42, 1927.

ARGAN, Giulio C. Ideology and iconology. In: The language of images. Chicago, William J.T. Mitchell, 1980.

AUERBACH, Erich. Figura (1933). In: Scences from the drama of European literature. New York, 1959. 
BERGERON, David M. Baconís Henry VII: commentary on King James I. Albion. 24, 1992.

BORIMSKI, Karl. Die Welwiedergeburtsidee. Munich, 1919.

BOUWSMA, William. Concordia Mundi: the career and thought of Guillaume Postel. Cambridge, Mass., 1957.

BRADING, David. The first America. Cambridge, 1991.

BRANDT, Gerard. Leven van Vondel. Amsterdam, S. Leendert Jr., 1932.

BREDVOLD, Louis. The intellectual mileu of John Dryden. Michigan, 1934.

BUCKELY, Anthony. We're trying to find our identity: uses of history among Ulster protestant's. History and ethnicity. Elizabeth Tonkin et al. (ed.), New York, 1989.

BURDACH, Konrad. Reforma, renaissance, humanismus. Berlin, 1918.

BURKE, Peter. The renaissance sence of the past. Londres, 1969.

. The rise of literal-mindednesse. In: Common Knowledge, 2, 1993.

BURROW, John. A liberal descent: Victorian historians and the English past. Cambridge, 1981.

CAMPBELL, L.B. The use of historical patterns in the Reign of Elizabeth. Huntington Library Quartely, 1938.

CHAMBERS, David. The imperial age of Venice. London, 1971, ch 1.

CHARITY, A.C. Events and their afterlife. Cambridge, 1966.

CHASTEL, André. French renaissance art in a European Contex. Sixteenth-Century Journal, 12, 1981.

CHURCH, William F. Richelieu and reason of State. Princeton, 1972.

DANIÉLOU, Jean Sacramentum futuri. Paris, 1950.

FIRTH, K.R. The apocalyptic tradition in Reformation Britain. Oxford, 1979.

FOUCAULT, 1. The order of things (1966). English trans., London, 1970.

GIBBS, Grahan C. Some intellectual and political influences of the huguenot emigrés in the United Provinces. Bijdragen en Mededelingen betreffende de Geschiedenis der Nederlanden, 90, 1975.

GILBERT, Mary E. Carolus Stuardus. German life and letters 3, 1950.

GORDON, D.J. Ripa's Fate. In: Renaissance imagination. Berkeley, 1975.

GRELL, Chantal \& MICHEL, C. L'école des princes on Alexandre disgracié. Paris, 1988.

GROENHUIS, G. The Dutch Republic as the New Israel. In: Church and State since the Reformation. The Hague, Ed. Alasdair Duke and Coen Tamse, 1981. 
HALLER, Willian. The elect Nation. London, 1963.

HAMMER, W. The concept of the new or second Rome in the Middle Ages. Speculum 19, 1994, for Trier, Tanner, 1993.

HANSON, R.P.C. Allegory and event, 1959.

HARPRATH, R. Papst Paul III als Alexander der Grosse. Berlin, 1981.

HARRIS, Victor. Allegory to analogy. In: Philological Quartely, 45. 1966.

HASKELL, Francis. The manufacture of the past in nineteenth-century-painting. In: Past \& Present, 53, 1971.

HAZARD, Paul. The European mind 1680-1715 (1935), English trans. London, 1947.

JONES, Roger \& PENNY, Nicholas. Raphael. New Haven and London, 1983.

JOUTARD, Philippe. La Saint-Barthélemy: ou les résonances d'un massacre. Neuchatel, 1976.

JÜRGEN, Hans. Antichirst, Weltheilsgescheden und Gotteswerkzeng. Wisbaden, 1978.

KNOWLES, David. Archbishop Thomas Becket. In: Proceedings of the British Academy $35,1949$.

KOLAKOWSKI, Leszek. Chétiens sans Eglise. Paris, French trans., Paris, 1969.

LLEO CAÑAL, Vicent. Nueva Roma: mitología y humanismo en el renacimiento sevillano. Seville, 1979.

MARX, B. Venezia - Altera Roma? Centro Tedesco di studi veneziani, Quaderni, 10, 1978.

MEINECKE, Friedrich. Historism. (1936). English trans., Londres, 1972.

NEALE, J.E. Queen Elizabeth (1934). Harmondswort, 1960.

NICHOLS JR., Stephen G. Romanesque signs. New Haven, 1983.

NICOLSON, Marjorie The breaking of the circle. Evanston, 1950.

OBEYESEKERE, Gananath. The apotheosis of captain Cook. Princeton, 1992.

PAULSON, Ronald. Emblem and expression. Londres, 1975.

PÉPIN, J. Mythe et allégorie. Paris, 1958.

POLLEROSS, Friedrich B. Das Sakrale Identifikationsporträt. 2 v., Worms, 1988.

POWELL, Hugh. The two versions of Andreas Gryphius' Carolus Stuardus. German life and letters 5, 1952.

REEDY, Gerard. Mystical Politcs. In. Studies in Change. P.J.Korshin, London, 1993.

REEVES, Donald Weinstein. Savonarola and Florence. Prophecy and Patriotism in the renaissance. Princeton, 1970. 
REEVES, Marjorie. The influence of prophec in the later middle ages. A study of Joachimism. Oxford, 1969.

ROLANDINO, apud J.K.Hyde. Padua in the age of Dante. Manchester, 1966.

ROSTON, M. Biblical drama in England, 1968.

SAHLINS, Marsall. Islands of history. Chicago, 1985.

Historical metaphors and mythical realities. Ann Arbor, 1981.

SALMON, John H.M. The French wars in English political thought. Oxford, 1959.

SCHAEDER, H. Moskau das dritte Rom, 1929.

SCHAMA, Simon. The embrassment of riches. London, 1987.

SCHÖNE, Albrecht. Emblematik und drama im Zeitalter des Barock. Munich, 1964.

STRAYER, Joseph. France: the holdy land, the chosen people, and the most cristian king. In: Ted Rabb \& Jerry Seigel, Action and conviction in Early Modern Europe. Pricenton, 1969.

TANNER, Marie. The last descendants of Aeneas: the Hapsburgs and the mythic image of the emperor. New Haven, 1993.

TREITINGER, O. Die Oströmische Kaiser- und Reichsidee (1938), Darmstadt, 1956.

TROMPF, G.W. The idea of historical recurrence in western thought from antiquity to the reformation. Berkeley, 1979.

TUVESON, Ernest. Reemer Nation. Chicago, 1968.

WACHTEEL, Nathan. The vision of the vanquished, 1971. English trans., Hassocks, 1977.

WARNER, Marina. Joan of Arc. London, 1981.

WHITE, Hayden. Metahistory. Baltimore, 1973.

WILLEY, Basil. The seventeenth-century background. London, 1934.

WOMERSLEY, David J. Sir John Haywardís tacitism. In: Renaissance Studies 6, 1992.

YATES, France. Queen Elizabeth as Astraea (1947). Repr in Astrae. Londres, 1975.

ZWICKER, Stephen. Politics and language in Drydenis poetry. Princeton, 1984.

\section{Resumo}

Neste artigo abordam-se as diferentes circunstâncias nas quais se tecem comentários sobre um evento (geralmente no passado) quando os comentadores estão, na verdade, preocupados com um outro evento (geralmente no presente). Nele, distingue-se a alegoria pragmática - que se encontra onde quer que haja restrições à liberdade de agilidade 
política - da alegoria mística - que pressupõe algum tipo de conexão oculta entre os dois acontecimentos. Este segundo tipo de alegoria entrou em declínio no fim do século XVII, mas poderá permanecer mais influente do que todos nós pensamos.

Abstract

This article is concerned with the different circunstances in wich comments are made as one event (usually in the past) when the commentators are really preoccupied with another (usually in the present). It distinguishes pragmatic allegory, to be found whenever there are restrictions on freedom of political speed, from mystical allegory, which assumes some kind of occult connection between the two events. This second kind of allegory has been in decline since the end of the seventeenth century, but it may remain more influential on us all than we think.

Peter Burke, historiador, é professor da Universidade de Cambridge, na Inglaterra, e autor de mais de 30 livros, muitos deles publicados no Brasil: A escola dos Annales(UNESP), Amsterdã e Veneza: um estudo das elites do séculos XVII (Brasiliense), A cultura popular na idade moderna (Companhia das Letras) e $A$ fabricação do rei: a construção da imagem pública de Luis XIV (Jorge Zahar). Foi professor visitante do IEA-USP de setembro de 1994 a setembro de 1995, período em que desenvolveu o projeto de pesquisa Duas crises de consciência histórica.

Palestra feita pelo autor em 18 de novembro de 1994 no IEA-USP. O autor agradece a Alex Pott por seus comentários sobre a versão original deste trabalho.

Traducão de Martha Steinberg. O original em inglês - History as allegory - encontra-se à disposição do leitor no IEA-USP para eventual consulta. 